\title{
Retraction Note to: Mechanical and Bioactivity Assessment of Wollastonite/PVA Composite Synthesized from Bentonite Clay
}

\author{
L. A. Adams ${ }^{a, *}$, E. R. Essien ${ }^{b}$ **, and E. E. Kaufmann ${ }^{c}$ \\ ${ }^{a}$ Department of Chemistry, University of Lagos, Akoka, Lagos, Nigeria \\ ${ }^{b}$ Department of Chemical and Food Sciences, Bells University of Technology, Ota, Ogun, Nigeria \\ ${ }^{c}$ Department of Biomedical Engineering, School of Engineering Sciences, University of Ghana, Legon, Accra, Ghana \\ *e-mail: ladams@unilag.edu.ng \\ **e-mail: reggiessien@gmail.com
}

DOI: $10.1134 / \mathrm{S} 1087659619080017$

The authors, the editor, and the publisher have retracted this article [1] as it has been published by the same authors [2] due to miscommunication between the journal and the authors after submission. The editors and the publisher apologize for any inconvenience caused. All authors have agreed to this retraction.

[1] Adams, L.A., Essien, E.R. \& Kaufmann, E.E. Glass Phys Chem (2019) 45: 119. https://doi.org/10.1134/S1087659619020020

[2] Adams, L.A., Essien, E.R. \& Kaufmann, E.E. Cerâmica (2019) 65: 246.

http://dx.doi.org/10.1590/0366-69132019653742584 